\title{
PEDOGEOQUÍMICA EM PERFIS DE ALTERAÇÃO NA REGIÃO DE LAVRAS (MG). II - ELEMENTOS MENORES E ELEMENTOS DAS TERRAS RARAS ${ }^{(\mathbf{1})}$
}

\author{
M. P. C. LACERDA ${ }^{(2)}$, H. ANDRADE ${ }^{(3)}$ \& J . J . G. QUÉ MÉ NE UR (4)
}

\begin{abstract}
RESUMO
Na região de Lavras, MG, analisou-se o comportamento geoquímico dos elementos menores (E M) e elementos das terras raras (ETR) ao longo da evolução pedogenética em perfis de solos com horizonte B textural, individualizados a partir de rochas de composição ácida, intermediária e básica do substrato. Nos perfis, realizaram-se análises químicas de E M e ETR, avaliando perdas e ganhos pelo balanço químico de massa. O estudo possi bilitou o grupamento dos $\mathrm{E} \mathrm{M} \mathrm{em}$ duas classes: (a) mobilidade moderada a alta: perda da rocha fresca até o sólum; (b) mobilidade moderada: enriquecimento relativo e eventualmente real no sólum. O comportamento dos ETR revelou grande mobilidade ao longo da evolução dos perfis de alteração.
\end{abstract}

Termos de indexação: solos com horizonte B textural, espectrometria de fluorescência de raios-X (FRX), espectroscopia de emissão atômica com plasma de acoplamento indutivo (ICP), balanço químico, evolução pedológica.

(1) Parte da Tese de Doutoramento apresentada pela primeira autora ao Curso de Pós-graduação em Sol os e Nutrição de Plantas do Departamento de Ciência do Solo da Universidade Federal de Lavras - DCS-UFLA, com financiamento da FAPEMIG. Recebido para publicação em dezembro de 2000 e aprovado em agosto de 2001.

(2) Professora da Faculdade de Agronomia e Veterinária da Universidade de Brasília - FAV/UnB. Campus Darcy Ribeiro- ICC Sul. Caixa Postal 04508, CEP 70910-970 Brasília (DF). E-mail: marilusa@unb.br

(3) Professor do Departamento de Ciência do Solo da Universidade Federal de Lavras - UFLA. Caixa Postal 37, CEP 37200-000 Lavras (MG). E-mail: handrade@ufla.br

(4) Professor do Departamento de Geologia do I nstituto de Geociências da Universidade Federal de Minas Gerais - DG/IGC/UFMG. Av. Antônio Carlos, 6.627, Caixa Postal 2.608, CEP 31270-901 Belo Horizonte (MG). 


\title{
SUMMARY: PEDOGEOCHEMICAL IN ALTERATION PROFILES IN THE REGION OF LAVRAS, MINAS GERAIS. II - TRACE ELEMENTS AND RARE EARTH ELEMENTS
}

\begin{abstract}
The geochemical behavior of trace el ements (TE) and rare earth el ements (REE) was evaluated in the region of Lavras (MG), during the pedogenetic evolution in soil profiles with argillic horizons differentiated by acid, intermediate and basic compositions of the parent material. Chemical analyses of TE and REE wereperformed along theprofiles and gains and losses were evaluated through mass chemical balance. The study allowed to group the TE into two classes: (a) moderate to high mobility: Ioss from the consolidated rocks to thesolum; and (b) moderatemobility: rel ativeand occasionally real enrichments in the solum. The REE showed a great mobility throughout the evolution of the alteration profiles.
\end{abstract}

Index terms: soils with argillic horizon, X-ray fluorescence spectrometry (XRF), atomic emission spectroscopy with inductivecoupled plasm (ICP), chemical bal ance, pedological evolution.

\section{INTRODUÇÃO}

O ambiente natural de superfície é definido como a parte do globo terrestre cujas condições físicoquímicas permitem a ação do intemperismo, onde as rochas primárias estarão em permanente desequilíbrio, especialmente quando entram em contato com as águas meteóricas. Medianteestudos pedogeoquímicos, é possível compreender a distribuição e migração dos el ementos químicos e as reações quími cas envolvidas durante os processos de alteração intempérica e formação dos solos no ambiente natural de superfície (Carvalho, 1995).

As águas meteóricas que atuam no intemperismo químico contêm quantidades variáveis de oxigênio e dióxido de carbono dissol vidos, que são suficientes para reagirem com a maioria dos minerais constituintes das rochas, fazendo com que sejam formadas novas fases minerais estáveis às novas condições fisico-químicas (Carvalho, 1995). N Neste processo de meteorização de rochas e formação dos solos, alguns elementos químicos são el iminados e outros são concentrados.

O trabalho clássico de Goldschmidt (1934) evidencia que o comportamento dos diversos íons em reações de meteorização pode ser diretamente correlacionado com o potencial iônico $\phi=Z / r$; uma propriedade fundamental do el emento, relacionada com a el etronegatividade, em que $Z$ = valência er $=$ raio iônico do elemento. Tal autor demonstrou que o potencial iônico pode explicar razoavel mente os fenômenos relacionados com a distribuição de elementos entre os sedimentos e águas naturais. Baseando no potencial iônico, Goldschmidt (1934, 1937) dividiu os el ementos em três grupos: Grupo I - elementos (cátions) com baixo potencial iônico $(<3)$, tais como: $\mathrm{Na}, \mathrm{K}, \mathrm{Ca}$, Mg e outros (Cs, Rb, Ba, Pb, Sr, $\left.\mathrm{La}, \mathrm{Mn}^{2+}, \mathrm{Cu}, \mathrm{Fe}^{2+}, \mathrm{Li}\right)$, que tendem a permanecer em solução iônica, ainda que em valores de $\mathrm{pH}$ el evados, e geralmente são lixiviados do meio; Grupo II - el ementos com potencial iônico maior que os do grupol (entre 3 e 12), que se hidrolisam e precipitam com facilidade na forma de hidróxidos, tal como ocorre com o Be, Al, $\mathrm{Ti}, \mathrm{Zr}, \mathrm{Cr}$ e outros ( $\mathrm{Fe}^{3+}$, $\mathrm{Mn}^{4+}$, Th, Lu, Y, Sc, V, Ga, Hf, Sn, Mo, Nb, Si, Ni) e concentram-se no resíduo, e GrupollI - inclui os elementos de potencial iônico maior que 12, que constituem ânions com o oxigênio e tendem a permanecer em solução iônica. É o caso dos elementos $\mathrm{N}, \mathrm{C}, \mathrm{S}, \mathrm{P}$ e $\mathrm{B}$, que em áquas naturais formam ânions complexos, tais como $\mathrm{NO}_{3}{ }^{-}, \mathrm{CO}_{3}{ }^{2-}$, $\mathrm{SO}_{4}{ }^{2-}-\mathrm{PO}_{4}{ }^{3-}$.

O conceito de potencial iônico pode, então, explicar o comportamento dos elementos na meteorização de rochas e pedogênese, assinalando quais serão eliminados e quais serão concentrados (Besoain, 1985).

Com relação aos el ementos das terras raras, estes têm sido referidos na bibliografia como resistentes ao fracionamento diante dos processos intempéricos (Nance \& Taylor, 1977; Hanson, 1980; Henderson, 1984). Outros trabalhos, pelo contrário, têm mostrado que os el ementos das terras raras podem ser submetidos a transporte e fracionamento significativos, especialmente ao longo do próprio perfil e perante intemperismo intenso (Nesbitt \& Taylor, 1979; Duddy, 1980; Banfield \& Eggleton, 1989; Formoso et al., 1989; Gasparetto \& Menegotto, 1995).

A mobilidade dos el ementos químicos duranteos processos intempéricos é, então, significativa. Para avaliar a distribuição e migração desses el ementos quími cos ao longo da intemperização química, devese recorrer ao balanço químico de massa entre o material de origem e os produtos resultantes destas alterações. A determinação da mobilidade dos el ementos quími cos durante as al terações exógenas 
permite o estabelecimento da seqüência de mobilidade dos el ementos em determinado ambiente e mesmo em diversos horizontes do perfil de alteração (Carval ho, 1995).

Para auxiliar a interpretação do comportamento dos elementos químicos, pode-se recorrer às suas características geoquímicas, descritas em diversas obras, sobretudo nas de Hawkes \& Webb (1962), que abordam a ocorrência dos elementos nas rochas diversas, nos minerais primários esecundários, suas concentrações médias nestes e nos sol os e na água, suas associações geoquímicas, além das condições de mobilidade no ambiente superficial.

Apesar da importância da Pedogeoquímica em estudos de meteorização de rochas e formação de solos, não existem trabalhos que contemplem tal tema na região de Lavras (MG). Por essa razão, realizaram-seestudos pedogeoquímicos nesta região, em perfis de alteração de solos com horizonte $B$ textural, individualizados a partir da composição geoquímica ácida, intermediária e básica das rochas do substrato, com o objetivo de avaliar o comportamento geoquímico dos el ementos menores e el ementos das terras raras ao longo dos processos de alteração e pedogênese. Analisou-se a caracterização geoquímica dos perfis de alteração, desde a rocha fresca até o sólum, e avaliou-se o comportamento da mobilidade e distribuição dos elementos químicos analisados, bem como a quantificação de suas perdas e ganhos.

\section{MATERIAL E MÉTODOS}

Procedeu-se à amostragem ao longo dos perfis de alteração, nas rochas e seus diferentes estádios de alteração e os solos sobre elas desenvolvidos, individualizados em seus horizontes. Foram, também, col etadas amostras indeformadas em todos os horizonte para a determinação da densidade global. Considerando o grau de evolução, os solos com horizonte B textural foram escol hidos para este estudo por preservarem as características químicas e mineralógicas das rochas originais. Os perfis de alteração foram criteriosamente sel ecionados a partir da discriminação litoquímica e petrológica dos domínios geológicos de origem (composição ácida, intermediária e básica), quando desenvolvidos em relevo ondulado a forte ondulado, condição de desenvolvimento desta classe de solos na região de Lavras, estabelecida em trabalhos de correlação geomorfopedológica por Andrade et al. (1998).

Os perfis sel ecionados foram: ArgissoloVermel hoAmarelo distrófico- Perfil 1 (PVAd), formado a partir de rochas granitóides de composi ção granítica (rocha ígnea de composição ácida, teor de $\mathrm{SiO}_{2}>66 \%$ ) do Domínio geológico intitulado Granito de Itutinga (Queméneur, 1995; Lacerda, 1999); Argissolo
Vermelho eutrófico - Perfil 2 (PVe), desenvolvido sobre diorito milonitizado (rocha ígnea de composição intermediária, com 55 a $66 \%$ de $\mathrm{SiO}_{2}$ ) do Domínio geológico Diorito do Rosário (Queméneur, 1995; Lacerda, 1999), e Chernossolo Argilúvico férrico Perfil 3 (MTf), tendo como substrato um piroxenito granulitizado (rocha ígnea básica com teor de $\mathrm{SiO}_{2}$ entre 55 e 45\%) do Domínio geológico denominado Greenstone-belt de Lavras (Queméneur, 1995; Lacerda, 1999).

As coordenadas geográficas dos perfis são: perfil 1 - ArgissoloVermel ho-A marel o distrófico: 44035'28'W e2117'50"S; perfil 2 - Argissol oVermelho eutrófico: 44'53'00"W e 21016'38"S, e perfil 3 - Chernossolo Argilúvico férrico: 4502'56'W e 21ํ11'00"S.

\section{Análises geoquímicas}

Nas análises geoquímicas, as amostras de rocha fresca erocha alterada foram previamente britadas e pulverizadas em moinho de $\mathrm{W}$ no Centro de Pesquisas Manoel Teixeira da Costa/Instituto de Geociências/Universidade Federal de Minas Gerais - CPMTC/I GC/UFMG, individualizando-sealíquotas de cerca de $30 \mathrm{~g}$. As amostras de sol o foram secas ao ar e posteriormente pulverizadas manual mente em graal de ágata até atingirem granulometria menor que $0,105 \mathrm{~mm}$, com controle granulométrico por tamisagem a seco (tamis de 150 \#), sendo, também, individualizadas alíquotas de cerca de $30 \mathrm{~g}$.

As análises geoquímicas foram efetuadas no CPMTC/I GC/UFMG, utilizando-semétodos combinados de Espectrometria de Fluorescência de Raios-X (FRX) e Espectroscopia de Emissão Atômica com Plasma de Acoplamento I ndutivo (ICP).

Os elementos menores analisados foram: $\mathrm{Ba}, \mathrm{Ni}$, $\mathrm{Cr}, \mathrm{V}, \mathrm{Co}, \mathrm{Zn}, \mathrm{Mo}, \mathrm{Rb}, \mathrm{Sr}, \mathrm{Y}, \mathrm{Cu}, \mathrm{Zr}, \mathrm{Nb}$ ePb. Analisaramse, também, os seguintes el ementos das terras raras: La, Ce, Nd, Sm, Gd, Dy, Ho, Er, Yb e Lu.

\section{Teores absolutos - balanço químico de massa}

Para padronização analítica, os valores da densi dade da amostra foram incorporados no cál culo de perdas e ganhos dos el ementos da rocha original para os produtos alterados, de tal forma que se pudesse fixar a variação de volume. Foram, então, calculados os teores absolutos de cada componente quími co detoda a seqüência deal teração nos perfis 1 , 2 e 3 , utilizando os teores dos el ementos obtidos por meio da análise química e a medida da densidade das respectivas amostras, tanto para os elementos menores quanto para os el ementos das terras raras.

Para a aval iação quantitativa das perdas eganhos dos elementos químicos durante os processos pedogenéticos, procederam-se aos cálculos de balanço químico de massa. Para efeito de cál culo, para os teores de el ementos menores obtidos abaixo do limite de detecção do método analítico adotado, ou seja $<5 \mathrm{mg} \mathrm{kg}^{-1}$ e $<10 \mathrm{mg} \mathrm{kg}^{-1}$, estabel eceram-se valores arbitrários de 3 e $5 \mathrm{mg} \mathrm{kg}^{-1}$, respectivamente. 
Utilizou-se o cálculo isovolumétrico de balanço químico de massa proposto por Millot \& Bonifas (1955) e Bonifas (1959) que permite determinar as perdas e ganhos em termos absolutos dos el ementos constituintes do material, quando este é submetido à ação do intemperismo químico, pela expressão t\% $=100 \cdot\left[\left(d_{a} \cdot x_{a} / d_{0} \cdot x_{0}\right)-1\right]$; em que $t \%$ = taxa de mobilidade; $d_{a}=$ densidade para o produto de alteração; $d_{o}=$ densidade para o material original; $\mathrm{x}_{\mathrm{a}}=$ teor do el emento no produto de al teração, ex $\mathrm{x}_{\mathrm{o}}=$ teor do elemento no material original. O valor det define a percentagem de perda, quando negativo, e ganho, quando positivo, dos componentes químicos nos vários estádios de alteração em relação ao seu material original.

Este cálculo isovolumétrico (Millot \& Bonifas, 1955; Bonifas, 1959) é utilizado quando se têm evidências de quea variação de volumeé desprezível, revelando conservação da estrutura do material durante a alteração, sendo possível calcular a quantidade, em peso, de cada elemento por unidade de vol ume e compará-la com a quantidade no mesmo volume de rocha fresca.

O método foi utilizado com base nos estudos micropedológicos e mineralógicos realizados na mesma seqüência de amostras destes perfis de alteração, cujos métodos e resultados encontram-se detal hados em Lacerda (1999) e Lacerda et al. (2000), que permitiram aos autores diagnosticar razoável conservação de estrutura litológica nos estádios iniciais de alteração, ou seja, no alterito (horizontes pedológicos C). Na evolução da alteração, representada pelos horizontes de transição (horizonte BC) e sól um (horizonte $B_{t} e A$ ), esses autores observaram feições indicativas de preservação de vol ume, tais como: box works e aumento gradativo na proporção de vazios em relaçãoao plasma +esquel eto no fundo matricial .

\section{Análises físicas}

A determinação da densidade gl obal foi efetuada pelo método do torrão parafinado (EMBRAPA, 1979a), com três repetições por amostra.

\section{Características físicas e mineralogia dos perfis de alteração}

A mineralogia da seqüência de alteração destes perfis e suas características físicas foram anal isadas por Lacerda (1999) e Lacerda et al. (2000). O quadro 1 resumeas principais características físicas destes perfis.

Os fácies rocha-fresca dos perfis estudados apresentam a seguinte composição mineralógica:

- Perfil 1 (PVAd) - granitói de- mineralogia essencial: feldspato potássico (30\%), plagioclásio (35\%), quartzo (25\%), biotita e anfibólio relictual da série

Quadro 1. Características físicas dos perfis 1, 2 e 3

\begin{tabular}{|c|c|c|c|c|c|c|c|c|c|}
\hline \multirow{2}{*}{ Amostra } & \multirow{2}{*}{ Horizonte } & \multirow{2}{*}{ Profundidade } & \multirow{2}{*}{ Areia } & \multirow{2}{*}{ Silte } & \multirow{2}{*}{ Argila } & \multirow{2}{*}{ Silte/Argila } & \multicolumn{2}{|c|}{ Classificação textural } & \multirow{2}{*}{ D } \\
\hline & & & & & & & SBCS $(1)$ & EMBRAPA(2) $^{(2)}$ & \\
\hline & & $\mathrm{cm}$ & $\longrightarrow$ & $-\mathrm{g} \mathrm{kg}^{-1}$ & - & & & & $\mathrm{kg} \mathrm{dm}^{-3}$ \\
\hline \multicolumn{10}{|c|}{ Perfil 1 - Argissolo Vermel ho-Amarelo distrófico (PVAd) } \\
\hline A & A & $0-55$ & 500 & 320 & 180 & 1,78 & $\mathrm{fr}$ & médio & 1,38 \\
\hline B & $\mathrm{B}_{\mathrm{t}}$ & $55-95$ & 560 & 230 & 210 & 1,09 & fr-arg-aren & médio & 1,35 \\
\hline $\mathrm{BC}$ & $\mathrm{BC}$ & $95-130$ & 520 & 360 & 120 & 3,00 & fr-aren & médio & 1,27 \\
\hline $\mathrm{C}_{1}$ & $\mathrm{C}_{1}$ & $130-210$ & 660 & 280 & 60 & 4,67 & fr-aren & médio & 1,31 \\
\hline $\mathrm{C}_{2}$ & $\mathrm{C}_{2}$ & $210-310$ & 620 & 330 & 50 & 6,60 & fr-aren & médio & 1,25 \\
\hline \multicolumn{10}{|c|}{ Perfil 2 - Argissolo Vermel ho eutrófico (PVe) } \\
\hline A & A & $0-20$ & 300 & 400 & 300 & 1,34 & fr-arg & médio & 1,28 \\
\hline B & $\mathrm{B}_{\mathrm{t}}$ & $20-80$ & 200 & 440 & 360 & 1,22 & fr-arg a fr-arg-silt & médio a argiloso & 1,47 \\
\hline $\mathrm{BC}$ & $B C$ & 80-130 & 240 & 590 & 170 & 3,47 & fr-silt & médio & 0,97 \\
\hline $\mathrm{C}_{1}$ & $\mathrm{C}_{1}$ & $130-260$ & 260 & 650 & 90 & 7,22 & fr-silt & médio & 1,07 \\
\hline $\mathrm{C}_{2}$ & $\mathrm{C}_{2}$ & $260-430$ & 260 & 670 & 70 & 9,57 & fr-silt & médio & 1,06 \\
\hline $\mathrm{C}_{3}$ & $\mathrm{C}_{3}$ & $430-450$ & 320 & 600 & 80 & 7,50 & fr-silt & médio & 1,18 \\
\hline \multicolumn{10}{|c|}{ Perfil 3 - Chernossolo Argilúvico férrico (MTf) } \\
\hline A & A & $0-18$ & 480 & 360 & 160 & 2,25 & $\mathrm{fr}$ & médio & 1,25 \\
\hline $\mathrm{B}$ & $\mathrm{B}_{\mathrm{t}}$ & $18-55$ & 140 & 340 & 520 & 0,65 & arg & argiloso & 1,45 \\
\hline $\mathrm{BC}$ & $\mathrm{BC}$ & $55-85$ & 200 & 390 & 410 & 0,95 & arg & argiloso & 1,09 \\
\hline $\mathrm{C}_{1}$ & $\mathrm{C}_{1}$ & $85-120$ & 560 & 320 & 120 & 2,67 & fr-aren & médio & 1,09 \\
\hline $\mathrm{C}_{2}$ & $\mathrm{C}_{2}$ & $120-230$ & 700 & 260 & 40 & 6,50 & fr-aren & médio & 1,51 \\
\hline $\mathrm{C}_{3}$ & $\mathrm{C}_{3}$ & $230^{+}$ & 740 & 220 & 40 & 5,50 & areia-fr & arenoso & 2,16 \\
\hline
\end{tabular}

$\mathrm{D}=$ densidade global do solo, arg = argiloso, fr = franco, silt = siltoso, aren = arenoso. ${ }^{(1)}$ Classes texturais do material constitutivo de horizontes e perfis de solos, segundo Lemos \& Santos (1984), adotadas pela Sociedade Brasileira de Ciência do Solo - SBCS.

(2) Classificação textural simplificada, segundo EMBRAPA (1979b). 
hornblenda-edenita (5\%); mineralogia secundária (5\%): biotita, epidoto da série zoisita-pistacita e zoisita-clinozoisita, moscovita, sericita, carbonato, titanita, clorita e óxidos de ferro, e mineralogia acessória: zircão e allanita.

- Perfil 2 (PVe) - diorito milonitizado - mineralogia essencial: plagioclásio (40\%), anfibólio da série hornblenda-edenita (20\%), quartzo (9\%) efeldspato potássico (traços); mineral ogia secundária: epidoto da série zoisita-pistacita (15\%), biotita (5\%), titanita (5\%), sericita (5\%) e clorita (1\%), e mineral ogia acessória: zircão, apatita e óxidos de ferro e titânio.

- Perfil 3(MTf) - piroxenito granulitizado- mineralogia essencial: clinopiroxênio da série diopsídio-augita (30\%), anfibólio da série hornblenda-edenita (30\%), plagioclásio (35\%) e quartzo (traços); mineralogia secundária (5\%): anfibólio da série tremolitaactinolita/uralita, sericita, óxidos de ferro e de titânio, e mineralogia acessória: apatita.

A associação de argilominerais silicatados mostra a seguinte constituição:

- Perfil 1 (PVAd): illita (nos horizontes C, BC e $B_{t}$ ) e caulinita + gibbsita (ambos nos horizontes C, BC, $B_{t}$ eA).
- Perfil 2 (PVe): illita (nos horizontes C e BC), vermiculita com hidróxi nas entrecamadas + caulinita (ambos nos horizontes C, BC, $B_{t}$ e A) e gibbsita (desenvolvendo-se a partir do horizonte $\mathrm{BC})$.

- Perfil 3 (MTf): caulinita + talco + esmectita (horizontes $C_{3}, C_{2}, C_{1}, B C, B_{t} e A$ ).

\section{RESULTADOS E DISCUSSÃO}

Os resultados obtidos pela análise química pela FRX el CP para os perfis 1 (PVAd), 2 (PVe) e 3 (MTf) encontram-se listados nos quadro 2 (elementos menores), e 3 (elementos das terras raras). As amostras referem-se aos horizontes pedogenéticos $A$, B (considerados como fácies sól um), BC (considerado como fácies detransi ção) eC (considerado como fácie alterito). $\mathrm{R}_{1}$ corresponde ao fácies rocha alterada e $\mathrm{R}$ ao fácies rocha fresca de origem.

Os quadros 4 e 5 apresentam os teores absolutos dos el ementos traços e elementos das terras raras, respectivamente. Como a densidade da amostra é uma propriedade que reflete o grau de al teração de maneira sensível, foram elaborados diagramas de

Quadro 2. Dados analíticos (F RX e ICP) dos elementos menores - Perfis 1, 2 e 3

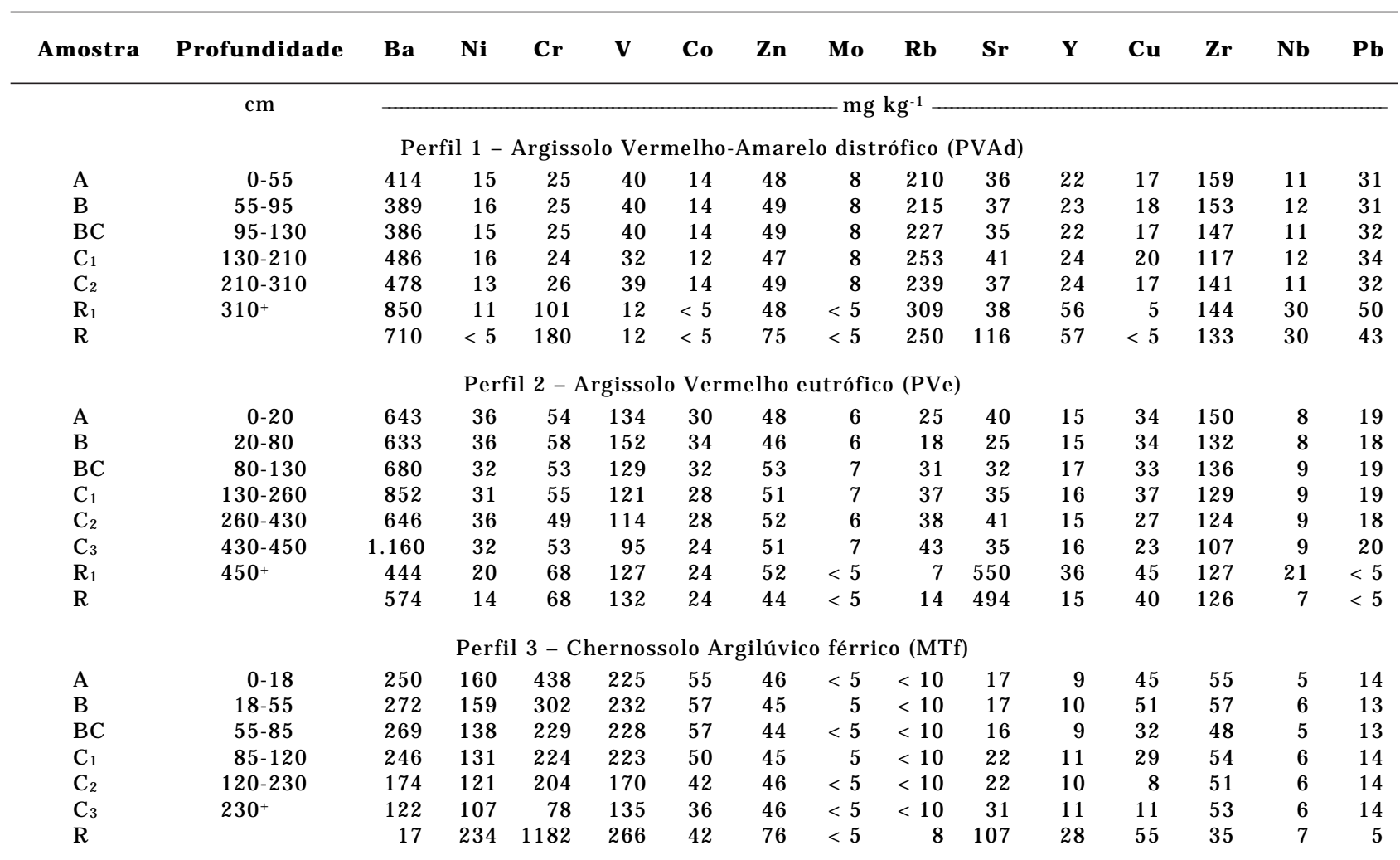

Sendo: $\mathrm{A}=$ horizonte $\mathrm{A}$ (fácies sólum), $\mathrm{B}=$ horizonte $\mathrm{Bt}$ (fácies sólum), BC = horizonte $\mathrm{BC}$ (fácies de transição), $\mathrm{C}=$ horizontes $\mathrm{C}$ (fácies alterito), $R_{1}=$ fácies rocha alterada, $R=$ fácies rocha fresca de origem. 
Quadro 3. Dados analíticos (ICP) dos elementos das terras raras - Perfis 1, 2 e 3

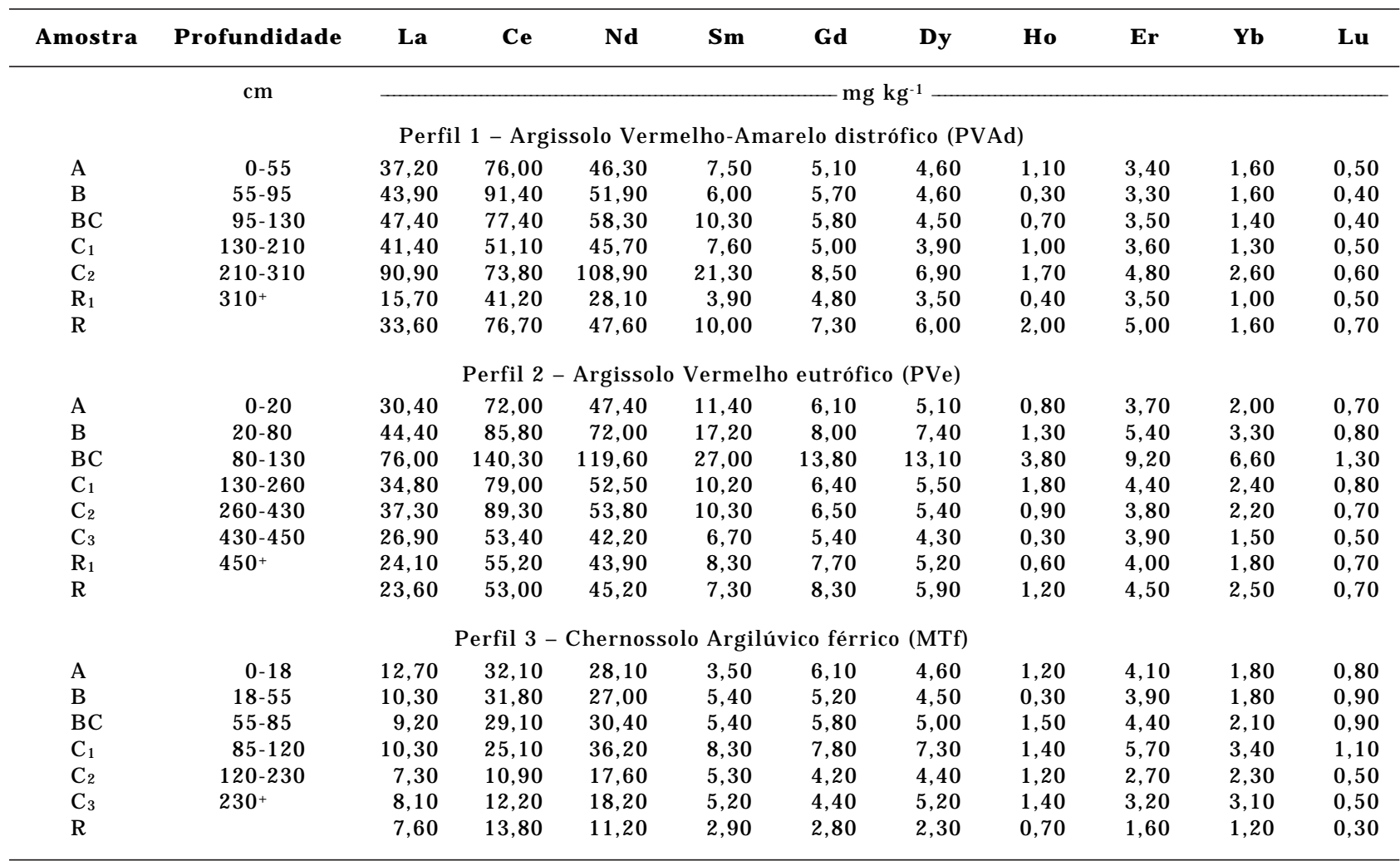

Sendo: $\mathrm{A}$ = horizonte $\mathrm{A}$ (fácies sólum), $\mathrm{B}=$ horizonte Bt (fácies sólum), BC = horizonte BC (fácies de transição), $\mathrm{C}=$ horizontes $\mathrm{C}$ (fácies alterito), $\mathrm{R}_{1}=$ fácies rocha alterada, $\mathrm{R}=$ fácies rocha fresca de origem.

teor absoluto dos elementos menores e elementos das terras raras versus densidade para os perfis 1, 2 e 3 (Figuras 1, 2, 3, 4, 5 e 6). Nestes diagramas, a densidade representa os diversos fácies dealteração avaliados ao longo dos perfis estudados, de acordo com a correspondência demonstrada nos quadros 4 e 5 .

Os valores de perdas e ganhos dos el ementos menores e elementos das terras raras encontrados pelo balanço químico de massa nos perfis 1,2 e 3 encontram-se nos quadros 6 e 7, respectivamente.

\section{Elementos menores}

Os teores absolutos dos el ementos menores (Quadro 4), os diagramas de sua distribuição de acordo com a densidade, correspondendo à seqüência da evolução da al teração ao longo dos perfis 1, 2 e 3 (Figuras 1, 2 e3), juntamente com o balanço químico (Quadro 6), permitem fazer as seguintes interpretações:

Ba-O teor absoluto deBa varia significativamente nos perfis 1, 2 e 3, com perda moderada, porém com variações ao Iongo da seqüência de alteração intempérica, atingindo, no balanço químico, cerca de 73 e $59 \%$ de perda em relação à rocha fresca de origem nos perfis 1 (PVAd) e 2 (PVe), respectivamente.
No entanto, no perfil 3 (MTf), o Ba apresenta ganho crescente da rocha fresca ao sólum, atingindo $675,92 \%$ de ganho no horizonte $B_{t}$ (Quadros 4 e 6 , Figuras 1, 2 e 3).

Sr e Rb - O Sr apresenta perda geralmente acentuada dos fácies dealteração rocha fresca/rocha alterada ao alterito, permanecendo a valores pouco variáveis a partir do alterito em direção ao sólum, atingindo valores de perda de 85,21, 97,77 e 94,55\%, respectivamente, nos perfis 1, 2 e 3 (Quadros 4 e 6, Figuras 1, 2 e 3).

O Rb apresenta comportamento semel hante ao Sr no perfil 1 (PVAd), atingindo 55,48\% de perda ao balanço químico no horizonte BC e, no perfil 3 (MTf), a perda da rocha fresca ao alterito é moderada, com maior percentagem de perda $(-77,22 \%)$ nos horizontes $C_{1}$ e BC. J á no perfil 2 (PVe), verifica-se pequeno incremento da rocha fresca ao alterito (+28,52\%) após uma perda no fácies de alteração rocha alterada $(-53,90 \%)$ e, a partir do alterito em direção ao sól um, os val ores absol utos variam pouco, refletindo no balanço químico ganhos discretos até o horizonte $C_{1}$, seguidos de perdas de até $32,98 \%$ no horizonte $B_{t}$ (Quadros 4 e 6, Figuras 1, 2 e 3).

$\mathrm{Zr}$ - O Zr mostra decréscimo dos teores absolutos ao longo das seqüências de alteração nos perfis 
Quadro 4. Teores absolutos dos elementos menores - Perfis 1, 2 e 3

\begin{tabular}{|c|c|c|c|c|c|c|c|c|}
\hline Amostra & D & $\mathbf{B a}$ & $\mathbf{R} \mathbf{b}$ & $\mathbf{S r}$ & $\mathbf{Z r}$ & $\mathbf{N i}$ & $\mathbf{C r}$ & Co \\
\hline \multicolumn{9}{|c|}{$-m g \mathrm{dm}^{-3}$} \\
\hline \multicolumn{9}{|c|}{ Perfil 1 - Argissolo Vermel ho-Amarelo distrófico (PVAd) } \\
\hline A & 1,38 & 571,32 & 289,80 & 49,68 & 219,42 & 20,70 & 34,50 & 19,32 \\
\hline B & 1,35 & 525,15 & 290,25 & 49,95 & 206,55 & 21,60 & 33,75 & 18,90 \\
\hline $\mathrm{BC}$ & 1,27 & 490,22 & 288,29 & 44,45 & 186,69 & 19,05 & 31,75 & 17,78 \\
\hline $\mathrm{C}_{1}$ & 1,31 & 636,66 & 331,43 & 53,71 & 153,27 & 20,96 & 31,44 & 15,72 \\
\hline $\mathrm{C}_{2}$ & 1,25 & 597,50 & 298,75 & 46,25 & 176,25 & 16,25 & 32,50 & 17,50 \\
\hline $\mathrm{R}_{1}$ & 2,28 & 1938,00 & 704,52 & 86,64 & 328,32 & 25,08 & 230,28 & 6,84 \\
\hline $\mathrm{R}$ & 2,59 & 1838,90 & 647,50 & 300,44 & 344,47 & 7,77 & 466,20 & 7,77 \\
\hline \multicolumn{9}{|c|}{ Perfil 2 - Argissolo Vermel ho eutrófico (PVe) } \\
\hline A & 1,28 & 823,04 & 32,00 & 51,20 & 192,00 & 46,08 & 69,12 & 38,40 \\
\hline B & 1,47 & 930,51 & 26,46 & 36,75 & 194,04 & 52,92 & 85,26 & 49,98 \\
\hline $\mathrm{BC}$ & 0,97 & 659,60 & 30,07 & 31,04 & 131,92 & 31,04 & 51,41 & 31,04 \\
\hline $\mathrm{C}_{1}$ & 1,07 & 911,64 & 39,59 & 37,45 & 138,03 & 33,17 & 58,85 & 29,96 \\
\hline $\mathrm{C}_{2}$ & 1,06 & 684,76 & 40,28 & 43,46 & 131,44 & 38,16 & 51,94 & 29,68 \\
\hline $\mathrm{C}_{3}$ & 1,18 & 1368,8 & 50,74 & 41,30 & 126,26 & 37,76 & 62,54 & 28,32 \\
\hline $\mathrm{R}_{1}$ & 2,6 & 1154,4 & 18,20 & 1430,00 & 330,20 & 52,00 & 176,80 & 62,40 \\
\hline $\mathrm{R}$ & 2,82 & 1618,68 & 39,48 & 1393,08 & 355,32 & 39,48 & 191,76 & 67,58 \\
\hline \multicolumn{9}{|c|}{ Perfil 3 - Chernossolo Argilúvico férrico (MTf) } \\
\hline$A$ & 1,25 & 312,50 & 6,25 & 21,25 & 68,75 & 200,00 & 547,50 & 68,75 \\
\hline B & 1,45 & 394,40 & 7,25 & 24,65 & 82,65 & 230,55 & 437,90 & 82,65 \\
\hline $\mathrm{BC}$ & 1,09 & 293,21 & 5,45 & 17,44 & 52,32 & 150,42 & 249,61 & 62,13 \\
\hline $\mathrm{C}_{1}$ & 1,09 & 268,14 & 5,45 & 23,98 & 58,86 & 142,79 & 244,16 & 54,50 \\
\hline $\mathrm{C}_{2}$ & 1,51 & 262,74 & 7,55 & 33,22 & 77,01 & 182,71 & 308,04 & 63,42 \\
\hline $\mathrm{C}_{3}$ & 2,16 & 263,52 & 10,80 & 66,96 & 114,48 & 231,12 & 168,48 & 77,76 \\
\hline \multirow[t]{2}{*}{$\mathrm{R}$} & 2,99 & 50,83 & 23,92 & 319,93 & 104,65 & 699,66 & 3534,18 & 125,58 \\
\hline & & $\mathrm{Cu}$ & Zn & $\mathbf{v}$ & Mo & $\mathbf{Y}$ & $\mathbf{N b}$ & $\mathbf{P b}$ \\
\hline \multicolumn{9}{|c|}{ Perfil 1 - Argissolo Vermel ho-Amarelo distrófico (PVAd) } \\
\hline A & 1,38 & 23,46 & 66,24 & 55,20 & 11,04 & 30,36 & 15,18 & 42,78 \\
\hline B & 1,35 & 24,30 & 66,15 & 54,00 & 10,80 & 31,05 & 16,20 & 41,85 \\
\hline $\mathrm{BC}$ & 1,27 & 21,59 & 62,23 & 50,80 & 10,16 & 27,94 & 13,97 & 40,64 \\
\hline $\mathrm{C}_{1}$ & 1,31 & 26,20 & 61,57 & 41,92 & 10,48 & 31,44 & 15,72 & 44,54 \\
\hline $\mathrm{C}_{2}$ & 1,25 & 21,25 & 61,25 & 48,75 & 10,00 & 30,00 & 13,75 & 40,00 \\
\hline $\mathrm{R}_{1}$ & 2,28 & 11,40 & 109,44 & 27,36 & 6,84 & 6,84 & 68,40 & 114,00 \\
\hline $\mathrm{R}$ & 2,59 & 7,77 & 194,25 & 31,08 & 7,77 & 147,63 & 77,70 & 111,37 \\
\hline \multicolumn{9}{|c|}{ Perfil 2 - Argissolo Vermelho eutrófico (PVe) } \\
\hline$A$ & 1,28 & 43,52 & 61,44 & 171,52 & 7,68 & 19,20 & 10,24 & 24,32 \\
\hline B & 1,47 & 49,98 & 67,62 & 223,44 & 8,82 & 22,05 & 11,76 & 26,46 \\
\hline $\mathrm{BC}$ & 0,97 & 32,01 & 51,41 & 125,13 & 6,79 & 16,49 & 8,73 & 18,43 \\
\hline $\mathrm{C}_{1}$ & 1,07 & 39,59 & 54,57 & 129,47 & 7,49 & 17,12 & 9,63 & 20,33 \\
\hline $\mathrm{C}_{2}$ & 1,06 & 28,62 & 55,12 & 120,84 & 6,36 & 15,90 & 9,54 & 19,08 \\
\hline $\mathrm{C}_{3}$ & 1,18 & 27,14 & 60,18 & 112,10 & 8,26 & 18,88 & 10,62 & 23,60 \\
\hline $\mathrm{R}_{1}$ & 2,6 & 117,00 & 135,20 & 330,20 & 7,80 & 93,60 & 54,60 & 7,80 \\
\hline $\mathrm{R}$ & 2,82 & 112,80 & 124,08 & 372,24 & 8,46 & 42,30 & 19,74 & 8,46 \\
\hline \multicolumn{9}{|c|}{ Perfil 3 - Chernossolo Argilúvico férrico (MTf) } \\
\hline A & 1,25 & 56,25 & 57,50 & 281,25 & 3,75 & 11,25 & 6,25 & 17,50 \\
\hline B & 1,45 & 73,95 & 65,25 & 336,40 & 7,25 & 14,50 & 8,70 & 18,85 \\
\hline $\mathrm{BC}$ & 1,09 & 34,88 & 47,96 & 248,52 & 3,27 & 9,81 & 5,45 & 14,17 \\
\hline $\mathrm{C}_{1}$ & 1,09 & 31,61 & 49,05 & 243,07 & 5,45 & 11,99 & 6,54 & 15,26 \\
\hline $\mathrm{C}_{2}$ & 1,51 & 12,08 & 69,46 & 256,70 & 4,53 & 15,1 & 9,06 & 21,14 \\
\hline $\mathrm{C}_{3}$ & 2,16 & 23,76 & 99,36 & 291,60 & 6,48 & 23,76 & 12,96 & 30,24 \\
\hline $\mathrm{R}$ & 2,99 & 164,58 & 227,24 & 795,34 & 8,97 & 83,72 & 8,97 & 14,95 \\
\hline
\end{tabular}

Sendo: $\mathrm{A}=$ horizonte $\mathrm{A}$ (fácies sólum), $\mathrm{B}=$ horizonte $\mathrm{Bt}$ (fácies sólum), BC = horizonte $\mathrm{BC}$ (fácies de transição), $\mathrm{C}=$ horizontes $\mathrm{C}$ (fácies alterito), $R_{1}=$ fácies rocha alterada, $R=$ fácies rocha fresca de origem. $D=$ densidade global. 
Quadro 5. Teores absolutos dos elementos das terras raras - Perfis 1, 2 e 3

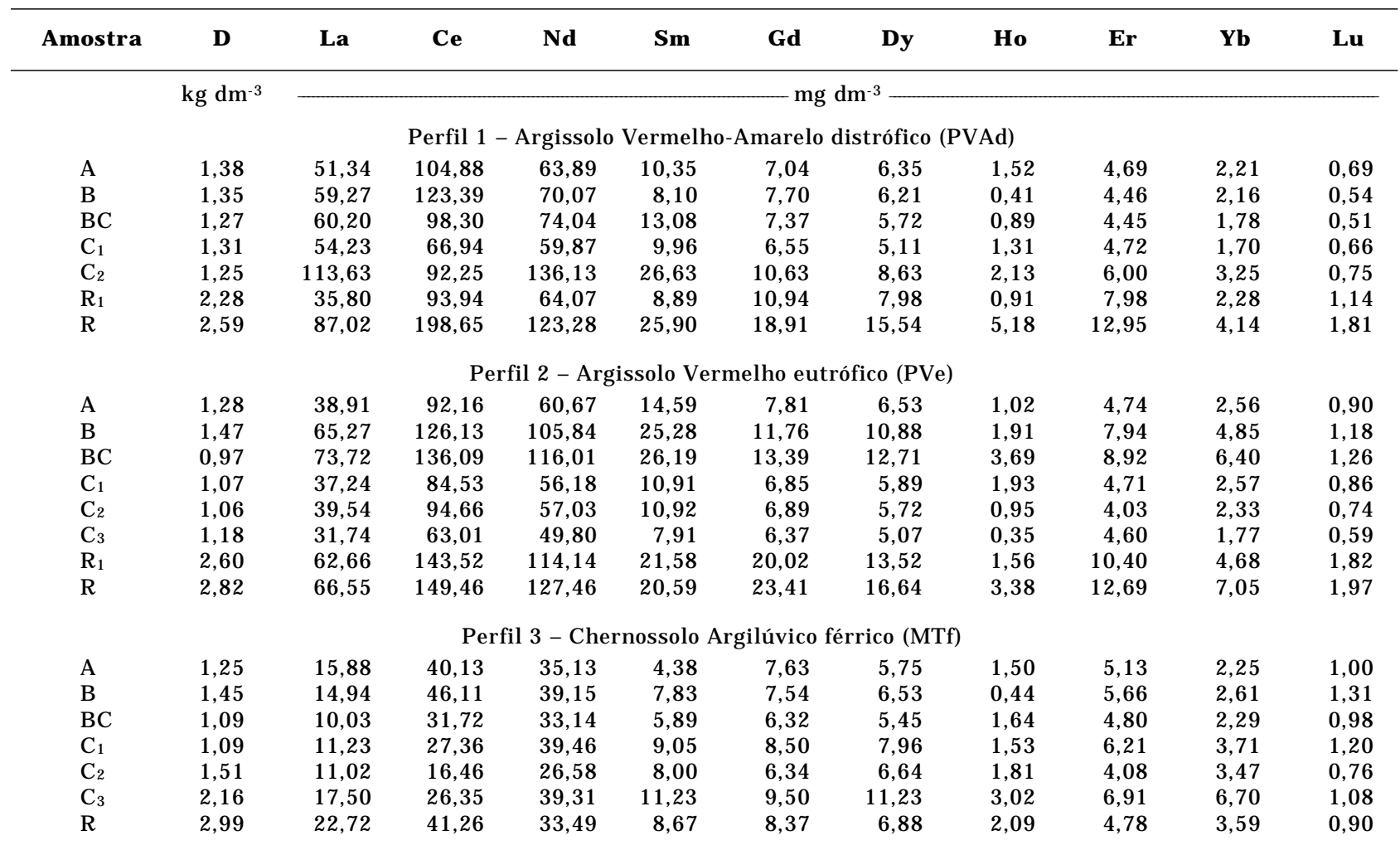

Sendo: $A=$ horizonte $A$ (fácies sólum), $B=$ horizonte $B t$ (fácies sólum), BC = horizonte BC (fácies de transição), $C=$ horizontes $C$ (fácies alterito), $R_{1}=$ fácies rocha alterada, $R=$ fácies rocha fresca de origem. $D=$ densidade global.

estudados, que seapresenta acentuado nos estádios iniciais da alteração, da rocha fresca/rocha alterada atéo alterito(Quadro 4,Figuras 1, 2 e3). Analisando o balanço químico (Quadro 6), as perdas em relação à rocha fresca de origem atingem 55,51; 64,47 e 50\% nos perfis 1, 2 e 3, respectivamente. A partir do horizonte de transição BC, verifica-seacréscimonos teores absolutos no sólum, especialmente no horizonte $\mathrm{B}_{\mathrm{t}}$, o que, no balanço químico, reflete-se nos menores valores de perda, indicando enriquecimento relativo (Quadros 4 e 6).

$\mathbf{N i}, \mathbf{C r}, \mathbf{C o}, \mathbf{C u}, \mathbf{V}$ e $\mathbf{Z n}$ - Nos perfis 2 (PVe) e 3 (MTf), estes elementos geralmente mostram incremento em seus teores absolutos, a partir do alterito em direção ao sólum, que se pronuncia no horizonte $B_{t}$, com subseqüente decréscimo em direção ao horizonte A (com exceção do $\mathrm{Cr}$ no perfil 3, aujo acréscimo prossegue rumo ao horizonte A). Esse incremento no sólum ocorre após decréscimo crescente, por vezes acentuado, nos estádi os iniciais da alteração, ou seja, dos fácies de alteração rocha fresca/rocha alterada ao alterito (Quadro 4 e Figuras 1, 2 e 3 ).

No perfil 3 (MTf), observa-se decréscimo crescente desses elementos da rocha fresca ao horizonte de transição $\mathrm{BC}$, com exceção do $\mathrm{Cr}$ e Cu.
No perfil 2 (PVe), nota-se perda mais acentuada da rocha fresca/rocha al terada ao al terito (horizonte $C_{3}$ ) para o V, Cr, Cu e Zn e estes, juntamente com os demais, permanecem em valores absolutos com pequenas variações a partir do alterito até o horizonte BC (Quadro 4 e Figuras 1, 2 e 3).

J á no perfil 1 (PVAd), verifica-se acréscimo nos teores absolutos desses el ementos, geralmente crescente, com algumas variações ao longo dos horizontes, desde a rocha fresca até o sólum, com exceção do $\mathrm{Cr}$ e $\mathrm{Zn}$. O subseqüente decréscimo no horizonte $A$ após acréscimo no horizonte $B_{t}$ é discretamente verificado somente para o $\mathrm{Cu}$ e $\mathrm{Ni}$ (Quadro 4 e Figuras 1, 2 e 3).

O balanço químico(Quadro 6) permitequantificar a mobilidade desses el ementos químicos. No perfil 1 (PVAd), verificam-se ganhos de $\mathrm{Ni}, \mathrm{Co}, \mathrm{Cu}$ e $\mathrm{V}$ ao longo de praticamente toda a seqüência dealteração, geralmente a partir do alterito, atingindo, respectivamente, percentagens de ganho de $+177,99$, $+148,65$, $+237,19$ e $+77,61 \%$, sendo esses maiores enriquecimentos preferencial mente no sól um. $\mathrm{O} \mathrm{Cr}$ e o $\mathrm{Zn}$ apresentam perdas da ordem de 93 e $67 \%$, respectivamente.

No perfil 2 (PVe), observa-se o ganho de $\mathrm{Ni}$ nos horizontes $\mathrm{B}_{\mathrm{t}}$ eA (34,04 e 16,72\%, respectivamente) 
Quadro 6. Balanço químico (isovolumétrico) para os elementos menores - Perfis 1, 2 e 3

\begin{tabular}{|c|c|c|c|c|c|c|c|c|}
\hline Amostra & D & $\mathbf{B a}$ & $\mathbf{R} \mathbf{b}$ & Sr & $\mathbf{Z r}$ & $\mathbf{N i}$ & $\mathbf{C r}$ & Co \\
\hline & $\mathrm{kg} \mathrm{dm}^{-3}$ & & 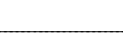 & 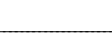 & $\%$ & 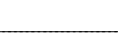 & & \\
\hline \multicolumn{9}{|c|}{ Perfil 1 - Argissolo Vermelho-Amarelo distrófico (PVAd) } \\
\hline A & 1,38 & $-68,93$ & $-55,24$ & $-83,46$ & $-36,30$ & 166,41 & $-92,60$ & 148,65 \\
\hline $\mathrm{B}$ & 1,35 & $-71,44$ & $-55,17$ & $-83,37$ & $-40,04$ & 177,99 & $-92,76$ & 143,24 \\
\hline$B C$ & 1,27 & $-73,34$ & $-55,48$ & $-85,21$ & $-45,80$ & 145,17 & $-93,19$ & 128,83 \\
\hline $\mathrm{C}_{1}$ & 1,31 & $-65,38$ & $-48,81$ & $-82,12$ & $-55,51$ & 169,76 & $-93,26$ & 102,32 \\
\hline $\mathrm{C}_{2}$ & 1,25 & $-67,51$ & $-53,86$ & $-84,61$ & $-48,83$ & 109,14 & $-93,03$ & 125,23 \\
\hline $\mathrm{R}_{1}$ & 2,28 & 5,39 & 8,81 & $-71,16$ & $-4,69$ & 222,78 & $-50,60$ & $-11,97$ \\
\hline $\mathrm{R}$ & 2,59 & 0,00 & 0,00 & 0,00 & 0,00 & 0,00 & 0,00 & 0,00 \\
\hline \multicolumn{9}{|c|}{ Perfil 2 - Argissolo Vermelho eutrófico (PVe) } \\
\hline$A$ & 1,28 & $-49,15$ & $-18,95$ & $-96,32$ & $-45,96$ & 16,72 & $-63,95$ & $-43,26$ \\
\hline B & 1,47 & $-42,51$ & $-32,98$ & $-97,36$ & $-45,39$ & 34,04 & $-55,54$ & $-26,15$ \\
\hline $\mathrm{BC}$ & 0,97 & $-59,25$ & $-23,83$ & $-97,77$ & $-62,87$ & $-21,38$ & $-73,19$ & $-54,14$ \\
\hline $\mathrm{C}_{1}$ & 1,07 & $-43,68$ & 0,28 & $-97,31$ & $-61,15$ & $-15,98$ & $-69,31$ & $-55,73$ \\
\hline $\mathrm{C}_{2}$ & 1,06 & $-57,70$ & 2,03 & $-96,88$ & $-63,01$ & $-3,34$ & $-72,91$ & $-56,58$ \\
\hline $\mathrm{C}_{3}$ & 1,18 & $-15,44$ & 28,52 & $-97,04$ & $-64,47$ & $-4,36$ & $-67,39$ & $-58,16$ \\
\hline $\mathrm{R}_{1}$ & 2,6 & $-28,68$ & $-53,90$ & 2,65 & $-7,07$ & 31,71 & $-7,80$ & $-7,80$ \\
\hline $\mathrm{R}$ & 2,82 & 0,00 & 0,00 & 0,00 & 0,00 & 0,00 & 0,00 & 0,00 \\
\hline \multicolumn{9}{|c|}{ Perfil 3 - Chernossolo Argilúvico férrico (MTf) } \\
\hline A & 1,25 & 514,79 & $-73,87$ & $-93,36$ & $-34,30$ & $-71,41$ & $-84,51$ & $-45,25$ \\
\hline $\mathrm{B}$ & 1,45 & 675,92 & $-69,69$ & $-92,30$ & $-21,02$ & $-67,05$ & $-87,61$ & $-34,19$ \\
\hline $\mathrm{BC}$ & 1,09 & 476,84 & $-77,22$ & $-94,55$ & $-50,00$ & $-78,50$ & $-92,94$ & $-50,53$ \\
\hline $\mathrm{C}_{1}$ & 1,09 & 427,52 & $-77,22$ & $-92,50$ & $-43,76$ & $-79,59$ & $-93,09$ & $-56,60$ \\
\hline $\mathrm{C}_{2}$ & 1,51 & 416,90 & $-68,44$ & $-89,62$ & $-26,41$ & $-73,89$ & $-91,28$ & $-49,50$ \\
\hline $\mathrm{C}_{3}$ & 2,16 & 418,43 & $-54,85$ & $-79,07$ & 9,39 & $-66,97$ & $-95,23$ & $-38,08$ \\
\hline $\mathrm{R}$ & 2,99 & 0,00 & 0,00 & 0,00 & 0,00 & 0,00 & 0,00 & 0,00 \\
\hline & & $\mathrm{Cu}$ & Zn & $\mathbf{v}$ & Mo & $\mathbf{Y}$ & $\mathbf{N b}$ & $\mathbf{P b}$ \\
\hline \multicolumn{9}{|c|}{ Perfil 1 - Argissolo Vermelho-Amarelo distrófico (PVAd) } \\
\hline A & 1,38 & 201,93 & $-65,89$ & 77,61 & 42,08 & $-79,44$ & $-80,46$ & $-61,59$ \\
\hline B & 1,35 & 212,74 & $-65,94$ & 73,75 & 39,00 & $-78,97$ & $-79,15$ & $-62,42$ \\
\hline $\mathrm{BC}$ & 1,27 & 177,86 & $-67,96$ & 63,45 & 30,76 & $-81,07$ & $-82,02$ & $-63,51$ \\
\hline $\mathrm{C}_{1}$ & 1,31 & 237,19 & $-68,30$ & 34,88 & 34,88 & $-78,70$ & $-79,77$ & $-60,01$ \\
\hline $\mathrm{C}_{2}$ & 1,25 & 173,49 & $-68,46$ & 56,85 & 28,70 & $-79,68$ & $-82,30$ & $-64,08$ \\
\hline $\mathrm{R}_{1}$ & 2,28 & 47,72 & $-43,65$ & $-11,97$ & $-11,97$ & $-95,37$ & $-11,97$ & 2,36 \\
\hline $\mathrm{R}$ & 2,59 & 0,00 & 0,00 & 0,00 & 0,00 & 0,00 & 0,00 & 0,00 \\
\hline \multicolumn{9}{|c|}{ Perfil 2 - Argissolo Vermelho eutrófico (PVe) } \\
\hline A & 1,28 & $-64,93$ & $-50,48$ & $-53,92$ & $-9,22$ & $-54,61$ & $-48,13$ & 187,47 \\
\hline B & 1,47 & $-59,72$ & $-45,50$ & $-39,97$ & 4,26 & $-47,87$ & $-40,43$ & 212,77 \\
\hline$B C$ & 0,97 & $-74,20$ & $-58,57$ & $-66,38$ & $-19,74$ & $-61,02$ & $-55,78$ & 117,85 \\
\hline $\mathrm{C}_{1}$ & 1,07 & $-68,09$ & $-56,02$ & $-65,22$ & $-11,47$ & $-59,53$ & $-51,22$ & 140,31 \\
\hline $\mathrm{C}_{2}$ & 1,06 & $-76,93$ & $-55,58$ & $-67,54$ & $-24,82$ & $-62,41$ & $-51,67$ & 125,53 \\
\hline $\mathrm{C}_{3}$ & 1,18 & $-78,13$ & $-51,50$ & $-69,89$ & $-2,36$ & $-55,37$ & $-46,20$ & 178,96 \\
\hline $\mathrm{R}_{1}$ & 2,6 & $-5,71$ & 8,96 & $-11,29$ & $-7,80$ & 121,28 & 176,60 & $-7,80$ \\
\hline $\mathrm{R}$ & 2,82 & 0,00 & 0,00 & 0,00 & 0,00 & 0,00 & 0,00 & 0,00 \\
\hline \multicolumn{9}{|c|}{ Perfil 3 - Chernossolo Argilúvico férrico (MTf) } \\
\hline A & 1,25 & $-65,80$ & $-74,70$ & $-64,64$ & $-58,19$ & $-86,56$ & $-30,32$ & 17,06 \\
\hline B & 1,45 & $-55,03$ & $-71,29$ & $-57,70$ & $-19,18$ & $-82,68$ & $-3,01$ & 26,09 \\
\hline $\mathrm{BC}$ & 1,09 & $-78,79$ & $-78,89$ & $-68,75$ & $-63,55$ & $-88,28$ & $-39,24$ & $-5,22$ \\
\hline $\mathrm{C}_{1}$ & 1,09 & $-80,78$ & $-78,41$ & $-69,44$ & $-39,24$ & $-85,68$ & $-27,09$ & 2,07 \\
\hline $\mathrm{C}_{2}$ & 1,51 & $-92,65$ & $-69,43$ & $-67,72$ & $-49,50$ & $-81,96$ & 1,00 & 41,40 \\
\hline $\mathrm{C}_{3}$ & 2,16 & $-85,55$ & $-56,28$ & $-63,34$ & $-27,76$ & $-71,62$ & 44,48 & 102,27 \\
\hline $\mathrm{R}$ & 2,99 & 0,00 & 0,00 & 0,00 & 0,00 & 0,00 & 0,00 & 0,00 \\
\hline
\end{tabular}

Sendo: $\mathrm{A}=$ horizonte $\mathrm{A}$ (fácies sólum), $\mathrm{B}=$ horizonte $\mathrm{Bt}$ (fácies sólum), BC = horizonte $\mathrm{BC}$ (fácies de transição), $\mathrm{C}=$ horizontes $\mathrm{C}$ (fácies alterito), $R_{1}=$ fácies rocha alterada, $R=$ fácies rocha fresca de origem. $D=$ densidade global. 

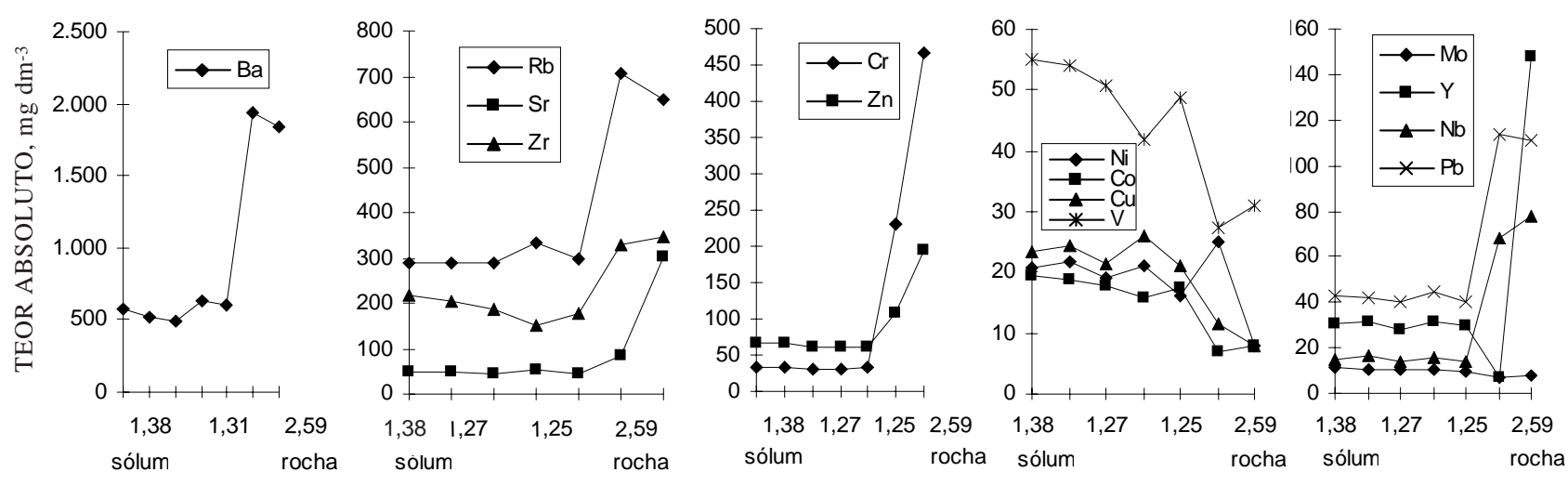

DENSIDADE, $\mathrm{kg} \mathrm{dm}^{-3}$

Figura 1. Diagramas de distri buição dos elementos maiores em teores absolutos em função da densidade para o perfil 1 - PVAd.
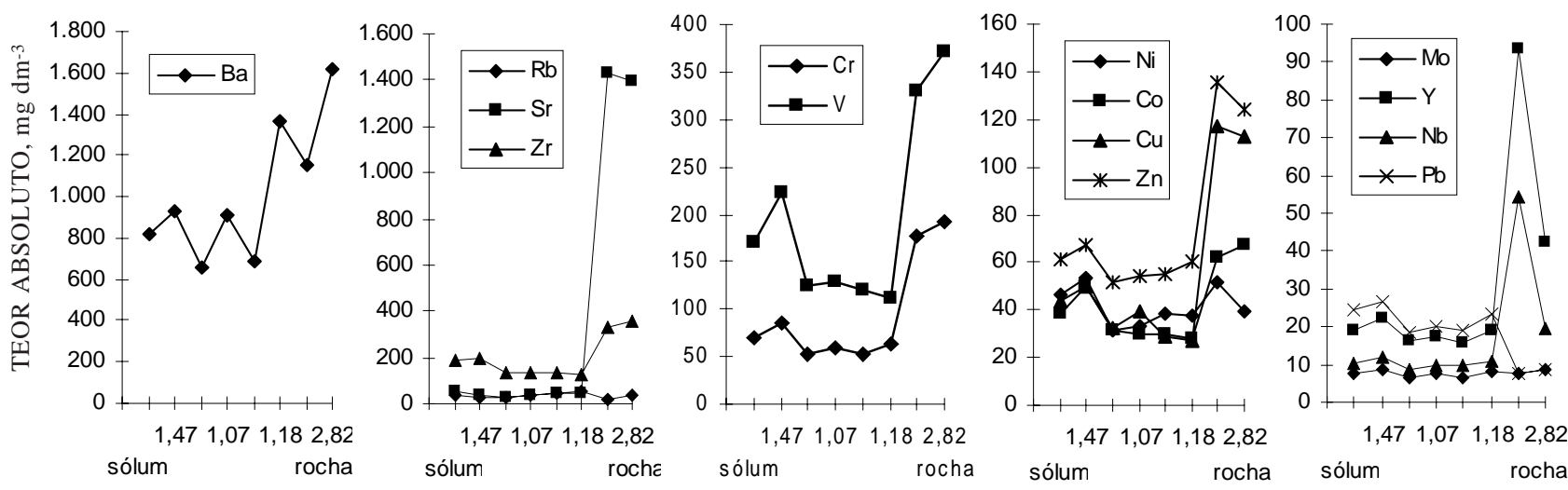

DENSIDADE, $\mathrm{kg} \mathrm{dm}^{-3}$

Figura 2. Diagramas de distri buição dos elementos maiores em teores absolutos em função da densidade para o perfil 2 - Pve.
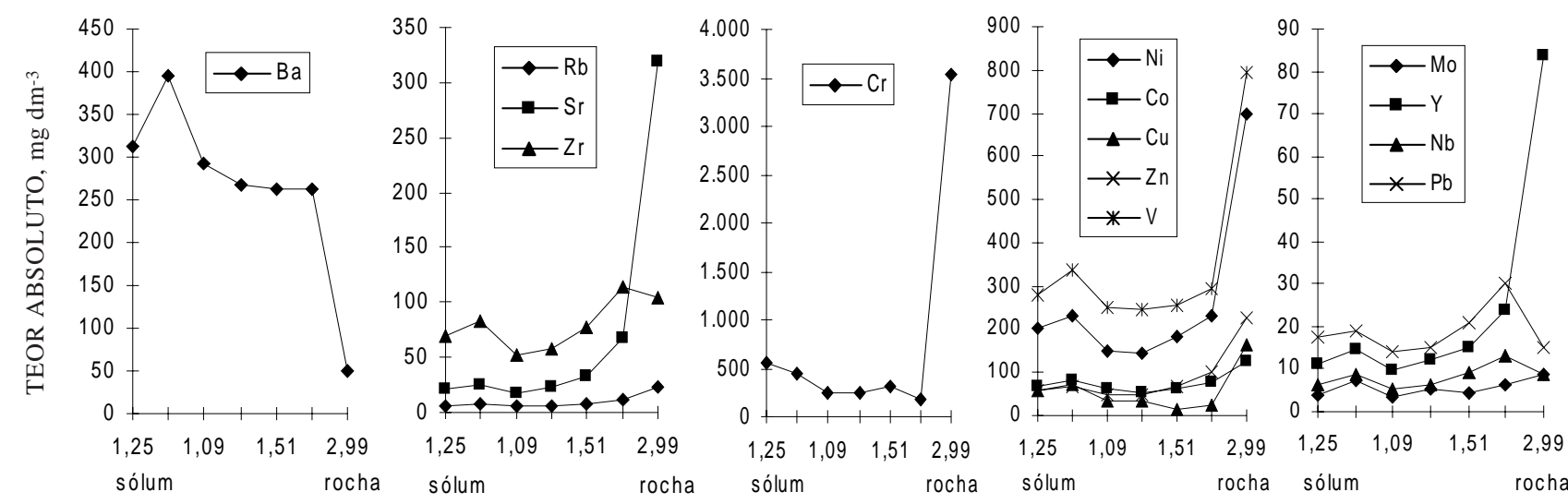

DENSIDADE, $\mathrm{kg} \mathrm{dm}^{-3}$

Figura 3. Diagramas de distribuição dos elementos maiores em teores absolutos em função da densidade para o perfil 3 - MTf. 
e os demais apresentam perda moderada em toda a seqüência dealteraçãoa partir doalterito, com perdas médias decerca de $67 \%$ para o $\mathrm{Cr}, 49 \%$ para oCo, $70 \%$ para o Cu, 53\% para oZn e $60 \%$ para oV. No entanto, verificam-se as menores perdas no horizonte $B_{t}, 0$ que indica enriquecimento relativo (Quadro 6).

J á no perfil 3 (MTf), ocorrem perdas desses elementos em toda a seqüência de alteração, com val ores médi os a partir do al terito de-74, -90,-47, -74, -75 e $-66 \%$, respectivamente, para $\mathrm{Ni}, \mathrm{Cr}, \mathrm{Co}, \mathrm{Cu}, \mathrm{Zn}$ eV. Todavia, podem-se verificar menores val ores de perda em direção ao sólum, especialmente no horizonte $\mathrm{B}_{\mathrm{t}}$, indicando enriquecimento relativo, tal como no perfil 2 (Quadro 6).

Mo, $\mathbf{Y}, \mathbf{N b}$ e $\mathbf{P b}$ - Estes elementos mostram comportamento semel hante ao descrito para $\mathrm{Ni}, \mathrm{Cr}$, $\mathrm{Co}$, Cu e $\mathrm{Zn}$, menos significativo, considerando os baixos teores absolutos, ou seja: acréscimo no horizonte $B_{t}$ com subseqüente decréscimo no horizonteA (pouco representativo no perfil 1 (PVAd)), a partir do alterito, e deste até o horizonte BC permanecendo valores com pequenas variações até o horizonte $\mathrm{B}_{\mathrm{t}}$. Para o $\mathrm{Y}$ e $\mathrm{Nb}$, esse incremento no sólum ocorre após decréscimo, por vezes acentuado da rocha fresca/rocha alterada ao alterito. $\mathrm{O} \mathrm{Pb}$ apresenta comportamento distinto nos perfis 2 (PVe) e 3 (MTf), com acréscimo da rocha fresca ao alterito, assim como o Mo no perfil 1 (PVAd) (Quadros 4 e 6, Figuras 1, 2 e 3).

Quanto ao balanço químico (Quadro 6), as perdas médias de $Y$ são cerca de 80, 56 e 83\%, respectivamente, para os perfis 1, 2 e 3; e de $\mathrm{Nb}$ são de 81 e $49 \%$, respectivamente, para os perfis 1 (PVAd) e 2 (PVe), ambos mostrando discretos menores val ores no horizonte $\mathrm{B}_{\mathrm{t}}$. O Nb no perfil 3 apresenta comportamento distinto, com perda moderada (máximo de-39,24\%) nos horizontes BC eA a baixa $(-3,01)$ no horizonte $B_{t}$, após ganhos de magnitude variáveis a partir da rocha fresca ao horizonte $C_{1}$. Os menores valores de perda no horizonte $B_{t}$ também indicam enriquecimento relativo desses el ementos.

O Mo no perfil 2 (PVe) apresenta perdas variáveis desde $-2,36$ até $-24,82 \%$, mostrando enriquecimento de $+4,26 \%$ no horizonte $B_{t}$, enquanto, no perfil 3 (MTf), as perdas são moderadas (média de $-45 \%$ ), com menor valor de perda no horizonte $B_{t}$. O perfil 1 (PVAd) é marcado por ganhos de Mo de até $+42,08 \%$ no sólum. O Pb apresenta ganhos nos perfis 2 (PVe) e 3 (MTf) de até 212,77 e 26,09\%, respectivamente, nos horizontes $B_{t}$, enquanto o perfil 1 (PVAd) mostra perdas médias de cerca de 62\% (Quadro 6).

A migração e a distribuição dos elementos químicos durante os processos de meteorização de rochas e formação de solos, conforme abordado por Carvalho (1995), foram verificadas nos três perfis avaliados. A distribuição dos elementos menores anal isados ao longo dos perfis de alteração mostrou a grande mobilidade desses elementos, evidenciando que, no processo pedogenético, alguns elementos podem ser eliminados e outros concentrados. No entanto, pode-sefazer o grupamento destes elementos de acordo com seu comportamento geoquímico:

- Classe I: Elementos de mobilidade moderada a alta, caracterizando perda da rocha fresca ao sólum, por vezes mais acentuada da rocha fresca ao alterito: $\mathrm{Rb}, \mathrm{Sr}$ e $\mathrm{Ba}$, este último nos perfis 1 (PVAd) e 2 (PVe).

- Classe II : Elementos de mobilidade moderada, com perda geral mente acentuada da rocha fresca ao alterito e enriquecimento relativo e eventualmente real no sólum, especialmente no horizonte $\mathrm{B}_{\mathrm{t}}: \mathrm{Ni}, \mathrm{Cr}, \mathrm{Co}, \mathrm{Cu}, \mathrm{Zn}, \mathrm{V}, \mathrm{Mo}, \mathrm{Y}, \mathrm{Nb}, \mathrm{Pb}$ eZr.

Essa subdivisão, baseada na mobilidade dos elementos menores avaliados, concorda, em linhas genéricas, com a subdivisão clássica proposta por Goldschimidt (1934, 1937), que correlaciona o comportamento dos elementos em reações de meteorização de acordo com o seu potencial iônico. Evidencia, também, conforme relata Besoain (1985), que a el etronegatividade dos el ementos pode indicar quais serão el iminados e quais serão concentrados durante a pedogênese.

Assim, a classe I é constituída por elementos de potencial iônico pequeno $(<3)$, correspondendo ao Grupo I proposto por Goldschimidt (1934, 1937), cujos elementos tendem a se solubilizar, sendo lixiviados do meio; enquanto os elementos agrupados na classe II apresentam potencial iônico maior que 3, correlacionados aos elementos do Grupo II de Goldschimidt (1934, 1937), que se hidrolisam e se precipitam geralmente na forma de hidróxidos.

Os el ementos agrupados na classe I (Ba, Rb eSr), de acordo com Hawkes \& Webb (1962), são elementos de mobilidade alta, corroborando o comportamento geoquímico verificado nos perfis estudados. Demodo geral, associam-seao K no fel dspato potássico; razão por que seus menores teores encontram-se na seqüência de alteração do perfil 3 (MTf), cuja rocha de origem praticamente não contém este mineral (L acerda, 1999; Lacerda et al., 2000) e, tal como o K, o comportamento geoquímico do Ba neste perfil fica comprometido.

$\mathrm{Na}$ classe II, o Ni, Cr, Co, Cu, Zn eV apresentam características geoquímicas semelhantes segundo Hawes \& Webb (1962), ocorrendo nas rochas em minerais ferromagnesianos ou como sul fetos eóxidos primários. J ustificam-se, assim, seus maiores teores no perfil 3 (MTf), originado de rocha básica, que revelam a maior proporção de minerais ferromagnesianos (clinopiroxênios e anfibólios) (Lacerda, 1999; Lacerda et al., 2000). Os menores teores destes elementos localizam-se no perfil 1 (PVAd), desenvolvido a partir de rocha granítica, estando os teores intermediários no perfil 2 (PVe), formado pela intemperização de rocha diorítica. Excetua-se oZn, queapresenta magnitude deteores praticamente equivalentes nos três perfis. 
Estes elementos, de modo geral, conforme discutido por Hawes \& Webb (1962), apresentam mobilidade variável nos solos; no entanto, esta é limitada pela co-precipitação com sesquióxidos de ferro. Precipitam-senos solos, então, como elementos menores nos sesquióxidos de $\mathrm{Fe}$, $\mathrm{Ti}$ e $\mathrm{Mn}$ e alguns deles, em especial o $\mathrm{Ni}$ e $\mathrm{Zn}$, em estruturas de argilominerais silicatados. Assim, fundamenta-seo comportamento geoquími co nos sol os aval iados, com enriquecimento real ou relativo desses el ementos nos horizontes $B_{t}$, acompanhando a concentração de sesquióxidos de ferro nesses horizontes, constatada em estudos mineralógicos realizados por Lacerda (1999) e Lacerda et al. (2000). Desta forma, esse enriquecimento relativo no horizonte $B_{t}$ é mais notório no perfil 3 (MTf) e subordinadamente no perfil 2 (PVe), por apresentarem maior concentração de sesquióxidos de Fe nos horizontes $B_{t}$.

Os el ementos $\mathrm{Mo}, \mathrm{Y}, \mathrm{Nb}$ e $\mathrm{Zr}$, também agrupados na classe II, são de pequena ocorrência nas rochas ígneas comuns, geralmente ocorrendo em minerais primários acessórios, tais como: sulfetos, molibdatos, fosfatos e silicatos, segundo Hawes \& Webb (1962). O mais comum em todos os tipos de rochas ígneas, especial mente as áci das e intermediárias, é o zircão $\left(\mathrm{ZrSiO}_{4}\right)$, que pode apresentar $\mathrm{Y}$ e $\mathrm{Nb}$ em sua composição química. Assim, podem-se justificar os maiores teores de $\mathrm{Zr}$ em associação com $\mathrm{Y}$ e $\mathrm{Nb}$ no perfil 1 (PVAd) de origem granítica (composição ácida), em que o zircão ocorre como mineral acessório comum, e os menores teores destes elementos são verificados no perfil 3 (MTf), originado de rocha de composição básica.

No solo, Mo, Y, Nb e Zr apresentam mobilidade variável, podendo ser limitada pela presença de sesquióxidos de $\mathrm{Fe}$, minerais argilosos silicatados e ferromolibdenita, no caso do Mo (Hawes \& Webb, 1962). O comportamento geoquímico discutido nos solos estudados, também com enriquecimento relativo e eventualmente real nos horizontes $B_{t}$, pode, então, estar relacionado com a maior concentração no sólum de sesquióxidos de Fe e possível enriquecimento relativo dezircão, queéum dos minerais mais resistentes ao intemperismo, além da maior concentração de argilominerais silicatados.

Nas rochas, o $\mathrm{Pb}$ participa da estrutura de micas e fel dspatos potássicos, além de sulfetos primários. Observa-se, então, o maior teor no perfil 1 (PVAd), que apresenta as maiores proporções de micas e feldspatos potássicos na sua constituição mineralógica original (Lacerda, 1999; Lacerda et al., 2000). No solo, deacordo com Hawes \& Webb (1962), apresenta mobilidade geralmente baixa, limitada, tal como nos elementos acima discutidos, pela copreci pitação com sesquióxidos de Fe, além da matéria orgânica. Pode-se, assim, compreender seu comportamento geoquími co nos sol os aval iados, com enriquecimento nos perfis 2 (PVe) e 3 (MTf), que apresentam maiores concentrações de sesquióxidos de Fe.

\section{Elementos das terras raras}

A distribuição dos elementos das terras raras (ETR) mostrou-se bastante variável ao longo dos perfis 1, 2 e 3, cujos teores absolutos encontram-se no quadro 5 . Os diagramas de distribuição de acordo com a densidade correspondem à seqüência da evolução da alteração ao longo dos perfis 1, 2 e 3 (Figuras 4, 5 e 6), enquanto o balanço químico é apresentado no quadro 7. Os dados geoquími cos dos elementos das terras raras mostram a mobilidade destes elementos no ciclo intempérico para as condições estudadas, concordando com as observações de Nesbitt \& Taylor (1979), Duddy (1980), Banfield \& Eggleton (1989), Formoso et al. (1989) e Gasparetto \& Menegotto (1995).

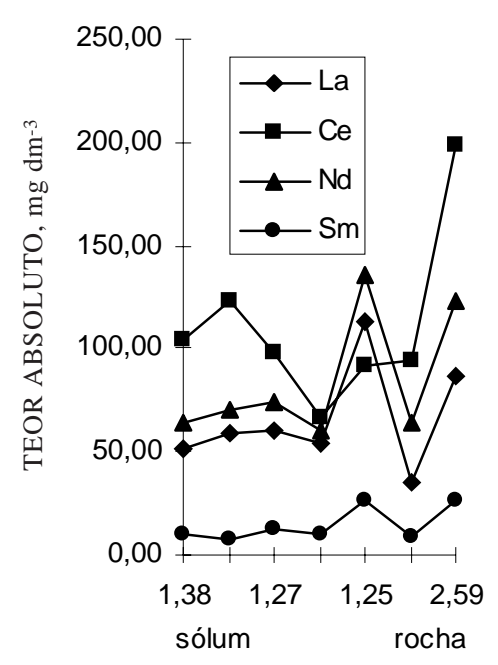

DENSIDADE, $\mathrm{kg} \mathrm{dm}^{-3}$

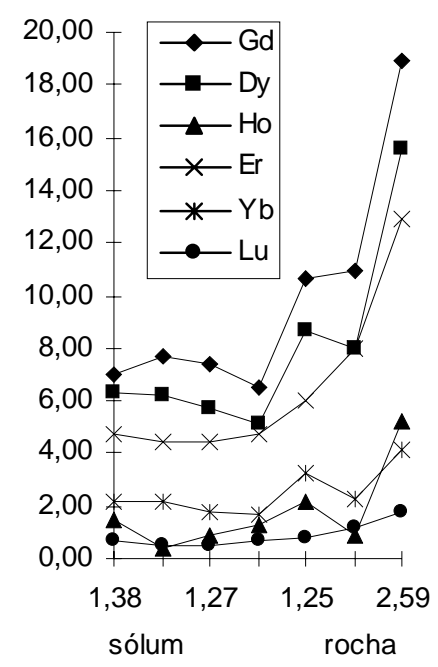

Figura 4. Diagramas de distribuição dos ETR em função da densi dade para o perfil 1 (PVAd). 


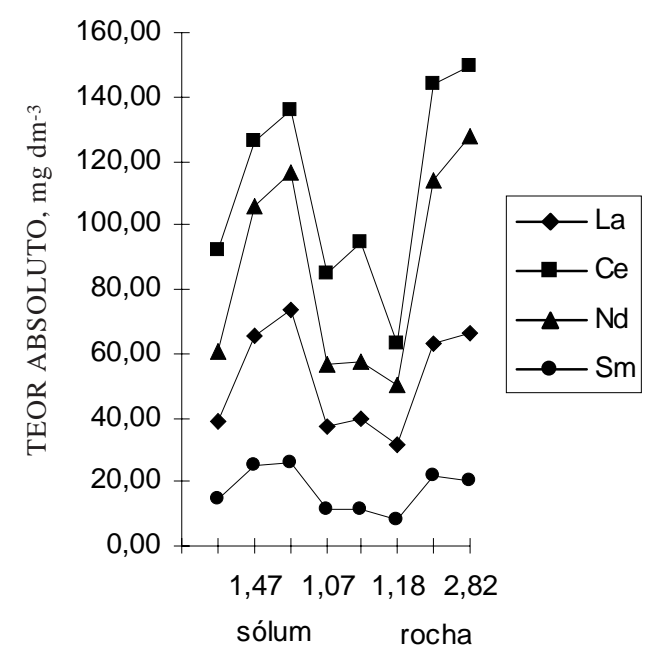

DENSIDADE, $\mathrm{kg} \mathrm{dm}^{-3}$

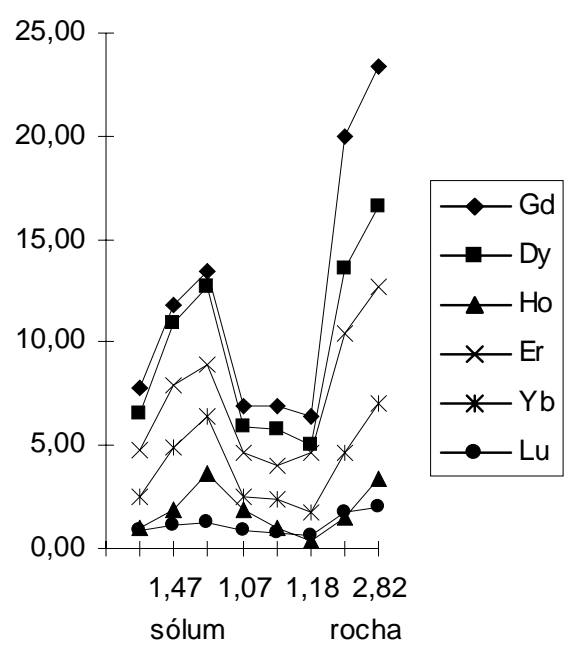

Figura 5. Diagramas de distribuição dos ETR em função da densidade para o perfil 2 (PVe).
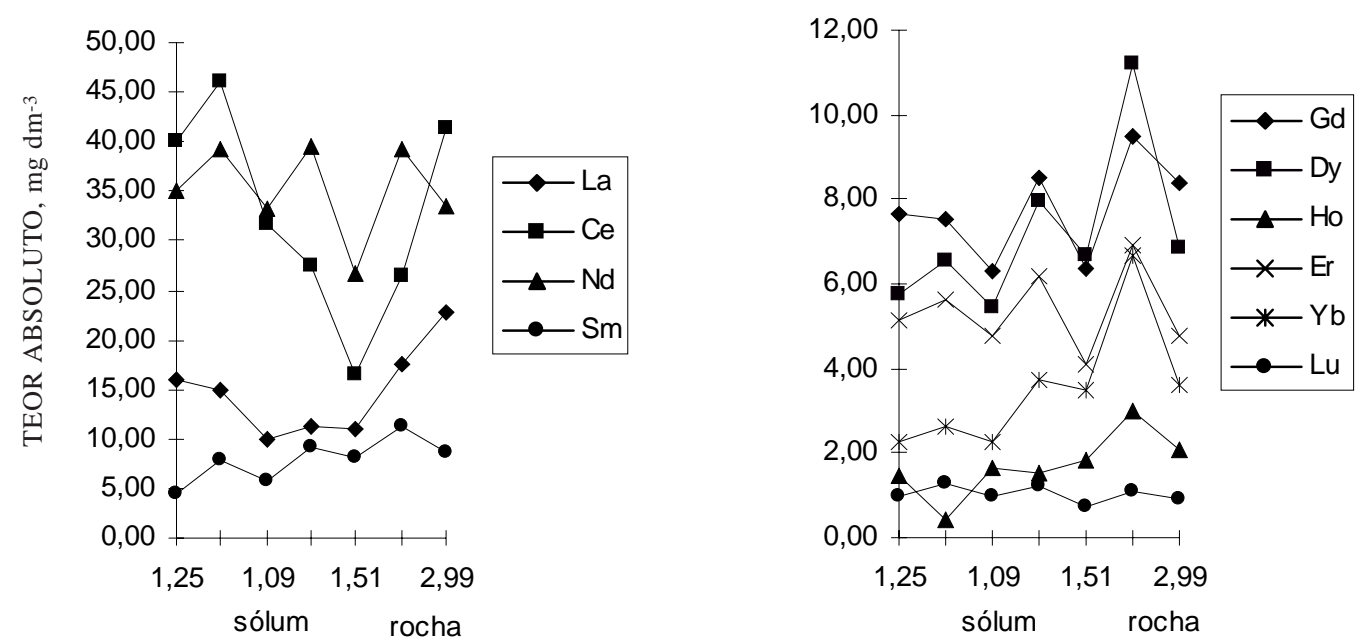

DENSIDADE, $\mathrm{kg} \mathrm{dm}^{-3}$

Figura 6. Diagramas de distribuição dos ETR em função da densidade para o perfil 3 (MTf).

No entanto, algumas tendências de distribuiç̧ão dos ETR podem ser discutidas. Ao longo da seqüência de alteração intempérica, a tendência genérica observada é a de perda, geralmente moderada, a partir da rocha fresca até o sólum, apesar das variações observadas ao longo dos horizontes pedogenéticos (Quadro 7).

O padrão de distribuição dos ETR no perfil 2 (PVe) segue a mesma tendência verificada para os elementos menores: perda da rocha fresca ao alterito (horizonte $\mathrm{C}_{3}$ ), permanecendo a valores absolutos praticamente equival entes até o horizonte $C_{1}$, seguidos de acréscimo em direção ao horizonte $B C$, com subseqüente decréscimo no sólum. Exceção é feita para o Lu, que mostra teores absolutos de pouca variação em toda a seqüência de alteração, considerando os seus baixos teores (Quadro 5, Figura 5). Quanto ao balanço químico (Quadro 7), as mai ores perdas são dos el ementos das terras raras pesadas, com valores em torno de $60-70 \%$, e os elementos das terras raras leves mostram perdas moderadas, da ordem de $40-50 \%$. Os ganhos do La, $\mathrm{Sm}$ e Ho e as menores perdas dos demais, incluindo o Lu, encontram-senos horizontes $\mathrm{BC}_{\mathrm{e}} \mathrm{B}_{\mathrm{t}}$ para todos os demais el ementos das terras raras, evidenciando enriquecimento relativo.

No perfil 1 (PVAd), podem-se distinguir dois padrões de distribuição, o primeiro nos ETR leves ( $\mathrm{La}, \mathrm{Ce}, \mathrm{Nd}$ e Sm), que apresentam perda da rocha fresca à rocha alterada, da ordem de 50 a $60 \%$, seguida de ganhos variáveis no horizonte $\mathrm{C}_{2}$ (com exceção do $\mathrm{Ce}$ ) e perdas moderadas (variando de 
Quadro 7. Balanço químico (isovolumétrico) para os elementos das terras raras - Perfis 1, 2 e 3

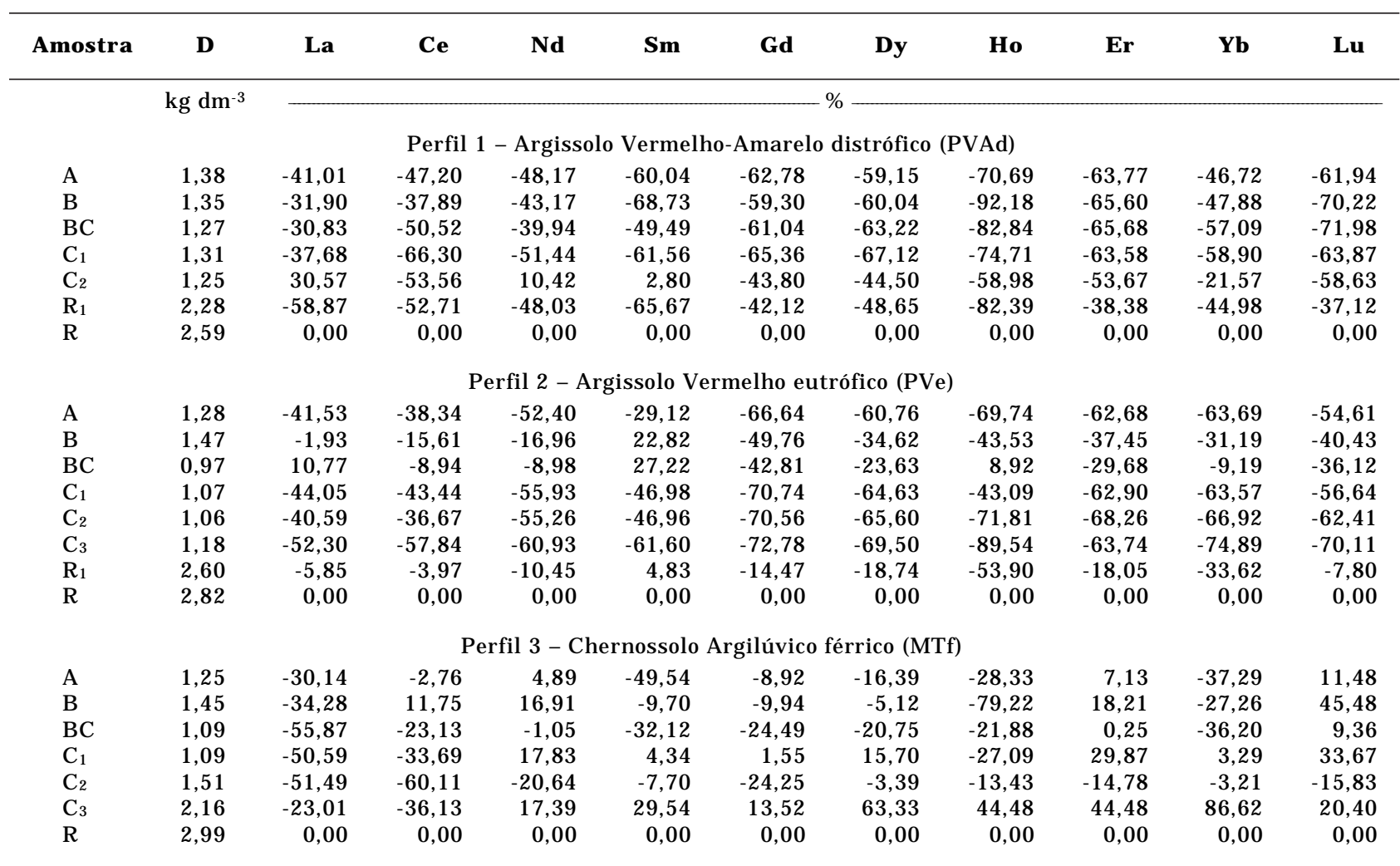

Sendo: $\mathrm{A}=$ horizonte $\mathrm{A}$ (fácies sólum), $\mathrm{B}=$ horizonte $\mathrm{Bt}$ (fácies sólum), BC = horizonte BC (fácies de transição), $\mathrm{C}=$ horizontes $\mathrm{C}$ (fácies alterito), $R_{1}=$ fácies rocha alterada, $R=$ fácies rocha fresca de origem. $D=$ densidade global.

cerca de 30 a 60\%) a partir do horizonte $C_{2}$. A partir deste, os valores permanecem pouco variáveis até o sólum, com exceção do Ce. O segundo padrão de distribuição refere-se aos ETR pesados (Gd, Dy, Ho, $\mathrm{Er}, \mathrm{Yb}$ e Lu), que mostram perda geralmente crescente, com variações ao longo dos horizontes, da rocha fresca ao sól um (perdas da ordem de 40 a $90 \%$ ). A distribuição dos teores absolutos ao longo da seqüência de alteração para o Lu apresenta-se tal como no perfil 2 (Quadro 5 e 7, Figura 4).

Já no perfil 3 (MTf), é difícil estabelecer um padrão de distribuição regular para os ETR, distribuição esta marcada por perdas e ganhos alternados ao longo dos horizontes que definem o perfil de alteração. A distribuição dos teores absolutos do Lu mostra poucas variações, tal como nos perfis 1 e 2 (Quadros 5 e 7, Figura 6).

Os dados geoquímicos dos elementos das terras raras mostram a mobilidade destes elementos no ciclo intempérico para as condições estudadas. Apesar de apresentarem potencial iônico $>3$, de acordo com a subdivisão proposta por Goldschimidt $(1934,1937)$, teriam tendência a formar hidróxidos. No entanto, os sol os com horizonte B textural, dado o seu grau de evolução, provavelmente não possibilitam a fixação dos ETR liberados dos minerais em outras partes dos perfis, impedindo sua concentração, concordando com as observações de Gasparetto \& Menegotto (1995).

A tendência genérica verificada é de perda, geralmente moderada, com algumas exceções. No perfil 2 (PVe), observa-se padrão mais uniforme de distribuição dos ETR, encontrando-se ganhos de La, $\mathrm{Sm}$ e Ho e as menores perdas para os demais ETR nos horizontes $\mathrm{BC}$ e $\mathrm{B}_{\mathrm{t}}$, evidenciando enriquedimento relativo.

Por meio desses resultados analíticos obtidos para os perfis 1, 2 e 3, foi possível avaliar a variação da composição química dos el ementos menores e das terras raras ao longo das seqüências de alteração, desde a rocha fresca até o sólum. Os cálculos volumétricos e bal anço químico de massa permitiram analisar o comportamento da mobilidade e distribuição dos elementos químicos avaliados ao longo da evolução pedogenética, bem como quantificar suas perdas e ganhos.

As magnitudes dos teores dos el ementos menores e elementos das terras raras ao longo dos perfis de al teração são compatíveis à composição química dos 
seus materiais originais, ou seja, rocha de composição ácida (granítica) para o perfil 1 - ArgissoloVermel hoAmarelo distrófico; rocha de composição intermediária (diorítica) para o perfil 2 - Argissolo Vermelho eutrófico, e rocha básica para o perfil 3 Chernossolo Argilúvico férrico. A variação química sofrida ao longo da seqüência de alteração pedogenética, da rocha fresca em direção ao sólum, é proporcional aos teores originais.

Noentanto, verifica-se comportamento geoquímico semel hante para os perfis em questão, que pode ser caracterizado como reflexo do processo pedogenético e grau de evolução dos solos com horizonte B textural. O comportamento geoquímico nos perfis avaliados émarcado, em linhas genéricas, pela perda acentuada da mai oria dos constituintes quími cos, nas primeiras fases da alteração, do fácies rocha-fresca ao alterito, mostrando que a alteração processa-se rapidamente a partir do início da atuação intempérica.

\section{CONCLUSÕES}

1. Os dados geoquímicos, obtidos ao longo das seqüências de alteração para os perfis 1 (PVAd), 2 (PVe) e 3 (MTf), mostram magnitudes compatíveis aos teores dos el ementos menores e elementos das terras raras com a composição geoquímica dos seus materiais de origem, com variação química aolongo das seqüências de alteração proporcional aos teores originais.

2. Os cál culos volumétricos e o balanço químico de massa permitiram a avaliação da mobilidade dos el ementos quími cos estudados ao longo da seqüência de evolução da al teração pedogenética, com estabel ecimento de perdas e ganhos. Verificou-se o comportamento geoquímico semel hante para os três perfis estudados, sendo caracterizado como reflexo do processo pedogenético e grau de evolução dos sol os com horizonte B textural.

3. O estudo possibilitou o grupamento dos elementos menores em duas classes de acordo com o comportamento geoquímico: Classe I - Elementos de mobilidade moderada-alta, caracterizando perda da rocha fresca ao sól um, por vezes mais acentuada da rocha fresca ao alterito: $\mathrm{Rb}, \mathrm{Sr}$ e Ba, este último nos perfis 1 (PVAd) e 2 (PVe) e Classe II - Elementos de mobilidade moderada, com perda geralmente acentuada da rocha fresca ao alterito e enriquecimento relativo e eventualmente real no sólum, especialmente no horizonte $\mathrm{B}_{\mathrm{t}}$ : $\mathrm{Cr}, \mathrm{Co}, \mathrm{Cu}$, $\mathrm{Zn}, \mathrm{V}, \mathrm{Mo}, \mathrm{Y}, \mathrm{Nb}, \mathrm{Pb}, \mathrm{Zr}$.

4. Verificou-se grande mobilidade dos el ementos das terras raras no ciclo intempérico para as condições estudadas. Os solos com horizonte B textural, dado o seu grau de evolução, provavelmente não possibilitam a fixação dos ETR liberados dos minerais em outras partes dos perfis, impedindo sua concentração.

\section{LITERATURA CITADA}

ANDRADE, H.; ALVES, H.M.R.; VIEIRA, T.G.C.; RESENDE, R.J.T.P.; ESTEVES, D.R; BRASIL, J.P.K. \& ROSA, E.R. Diagnóstico ambiental do município de Lavras com base em dados georreferenciados do meio físico: IV - Principais grupamentos de solos. In: CONGRESSO BRASILEIRO DE EngenHARI A AGRí COLA, 27., Poços de Caldas, 1998. Anais. Poços de Caldas, Universidade Federal de Lavras/ Sociedade Brasileira de Engenharia Agrícola, 1998, v.4. p.442-443.

BANFIELD, J.F. \& EGGLETON, R.A. Apatite replacement and rare earth mobilization, fractionation and fixation during weathering. Clays Clay Miner., 37:113-127, 1989.

BESOAIN, E. Mineralogía de arcillas de suelos. San J osé, Costa Rica, Instituto Interamericano de Cooperacion para la Agricultura, 1985. 1205p.

BONIFAS, M. Contribution à l'étude géochimique del'alteration latéritique. Mem. Serv. Carte Géol. d'Alsace et Lorraine, 17, 1959. 159p.

CARVALHO, I.G. Fundamentos da geoquímica dos processos exógenos. Salvador, Bureau Gráfica e Editora, 1995. 213p.

DUDDY, I.R Redistribution and fractionation of rare earth an other elements in a weathering profile. Chem. Geol., 30:363-381, 1980.

EMPRESA BRASILEIRA DE PESQUISA AGROPECUÁRIA EMBRAPA. Serviço Nacional de Levantamento e Conservação de Solos. Manual de método de análise de solo. Rio de J aneiro, 1979a. não paginado.

EMPRESA BRASILEIRA DE PESQUISA AGROPECUÁRIA EMBRAPA. Serviço Nacional de Levantamento e Conservação de solos. Súmula da X Reunião Técnica de Levantamento de Solos. Rio de J aneiro, 1979b. 83p. (SNLCS - Série Miscelânia, 1)

FORMOSO, M.L.L.; MELFI, A.J. \& KRONBERG, B.I. Comportamento dos elementos terras raras no intemperismo tropical. In: FORMOSO, M.L.L.; NARDI, L.V.S. \& HARTMANN, L.A., eds. Geoquímica dos el ementos terras raras no Brasil. CPRM/ DNPM/SBGq, 1989. p.109120.

GASPARETTO, N.V.L. \& ME NEGOTTO, E. Comportamento dos elementos terras raras na intemperização de rochas vulcânicas ácidas em dima subtropical. In: CONGRESSO BRASILEIRO DE GEOQUIMICA, 5.; CONGRESSO DE GEOQUIIMICA DOS PAÍSES DE LÍNGUA PORTUGUESA, 3., Niterói, 1995. Resumos. Niterói, Sociedade Brasileira de Geoquímica, 1995. (CD-ROOM)

GOLDSCHMIDT, V.M. Drei vorträge über geochemie. Geol. Fören. Förhandl., 56:385-427, 1934.

GOLDSCHMIDT, V.M. The principles of the distribution of chemical elements in minerals and rocks. J. Chem. Soc., 40:655-673, 1937. 
HANSON, G.N. Rare earth elements in petrogenetic studies of igneous systems. Ann. Rev. Earth Plan. Sci., 8:371-406, 1980.

HAWES, H.E. \& WEBB, J.S. Geochemistry in Mineral Exploration. New York, Elsevier, 1962. 377p.

HENDERSON, P. Rare earth element geochemistry. London, British Museum Natural History, 1984. 369p.

LACERDA, M.P.C. Correlação geo-pedológica em solos B texturais na região de Lavras, MG. Lavras, Universidade Federal de Lavras, 1999. 257p. (Tese de Doutorado)

LACERDA, M.P.C.; ANDRADE, H. \& QUEMÉNEUR, J.J.G. Micropedologia da alteração em perfis de solos com $B$ textural na região de Lavras, Minas Gerais. R. Bras. Ci. Solo, 24:829-841, 2000.

LEMOS, R.C. \& SANTOS, R.D. Manual de descrição e coleta de solo no campo. 2 ed. Campinas, Sociedade Brasileira de Ciência do Solo, 1984. 45p.
MILLOT, G. \& BONIFAS, M. Transformations isovolumetriques dans les phenomenes de laterisation et de bauxitisation. Bull. Serv. Carte Géol. d'Alsace et Lorraine, 8:3-20, 1955.

NANCE, W.B. \& TAYLOR, S.R. Rare earth element and crustal evolution. 2 - Archean sedimentary rocks from Lalfoorlie, Australia. Geochim. Cosmoch. Acta, 41:225-231, 1977.

NESBITT, H.W. \& TAYLOR, S.R. Mobility and fractionation of rare earth elements during weathering of a granodiorite. Nature, 279:206-210, 1979.

QUÉMÉNEUR, J.J.G. Os magmatismos de idade Arqueana e Transamazônica na Região Campo das Vertentes, MG (Sul do Cráton São Francisco), com base em geoquímica e geocronologia. Belo Horizonte, CPMTC/UFMG, 1995. 79p. (Relatório inédito) 